\title{
ADMINISTRAGÄO GERAL
}

\section{ORÇAMENTO}

\section{A Ciêncıa Econômica e a Teoria do Orçamento (*)}

(Os postulados da ciência econômica e a teoria do orçamento: possibilidade de aplicação dos primeiros à segunda).

\section{Augusto DE REzende Rocha}

(Técnico de Administração do D.A.S.P.)

1. Há, modernamente, duas correntes que se propõem fornecer definições de Economia e que dividem entre si o campo metodológico e teórico da disciplina. Porque não seja a nossa intenção precípua examinar desenvolvidamente o assunto, limitar-nos-emos a esquematizá-lo, sem que a fôrça e o proveito dos argumentos - pelo menos o esperamos - fiquem prejudicados.

Essas duas correntes do pensamento econômico, à semelhança do que fêz LINDLEY FRASER quando as analisou tão penetrantemente, (1) serão grupadas, para maior facilidade de referência, em tipo "A" e tipo "B". A primeira classe tipo $\mathrm{A}$, liga as suas definições ao conceito de riqueza ou de bem-estar material; a segunda - tipo B - ao de escassez.

São representantes distintos das definições do tipo A: J. N. KEyNES (Scope and Method of Political Economy). Alfred Marshall (Principles of Economics), DAVENPORT (Economics of Enterprise), CANNAN (Elementary Political Economy - Wealth), BEVERIDGe (Economics as a Liberal Education), A. G. Pigou (Economics of Welfere), Charles Gide (Principes d'Economie Politique), VILfredo PARETo (Cours d'Economie Politique) e muitos outros economistas que se mantêm fiéis, pelo menos em parte, à orientação dada à Economia por ADAM SMITH e RICARDO. As definições do tipo B foram propostas, entre outros, por LIONEL RoBbins (The Nature and Significance of Economic Science), P. H. WICKsTeEd (The Common Sense of Political Economy), L. VON Mises (Grundprobleme der Nationaloekonomie), Richard STRIGL (Die oekonomischen Kategorien und die Organisation der Wistschaft), ERICH RoLl (Elements of Economic Theory).

(*) Excerto do Capítulo I da Tese Orçamento - plano econômico-financeiro, ainda inédita e apresentada pelo autor, em maio de 1943, como requisito parcial, ao terceiro concurso de 'Técnico de Administração do Q.P. do D.A.S.P. O texto agora publicado reproduz $\circ$ que foi submetido à Comissão examinadora, sem qualquer modificação.

(1) Lindley Fraser, Economic Thought and Language, A. \& C. Black Ltd., Londres, 1937, cap. II, p. 21/45. (Magnifica exposição dos pontos essenciais e do estado atual da questão). 
$\mathrm{Na}$ exposição crítica que vamos empreender, acompanharemos, de preferência, a Lionel Robbins, (2) ERICH Roll, (3) e Lindley Fraser, que sintetizaram com extraordinária felicidade o estado atual da questão. Esta não é de maneira alguma - insistimos em reafirmá-lo - preocupação amável ou acadêmica, mas antes de fundamental importância para o progresso de economia pura e, talvez mesmo, da Economia aplicada. Permitir-nos-á, de resto, a análise que fizermos, conhecer a natureza do problema econômico e aclarar, conseguintemente, a do orçamento.

2. "A Economia é a ciência - declara J. N. Keynes que trata dos fenô. menos oriundos das atividades econômicas do homem em sociedade". (4) A Economia - diz o professor CANNAN - preocupa-se com o lado material da felicidade humana, ou, mais brevemente, diz respeito ao bem estar material. (5) Em outro livro, precisando melhor o pensamento, escreveu: "O propósito da Economia política é a explanação das causas gerais de que depende o bem estar material dos homens". (6) MarShall considera que a Economia é "o estudo do homem nos negócios comuns da vida; examina aquela parte da ação individual ou social que está ligada mais intimamente à obtenção e ao uso dos requisitos materiais do bem estar". (7)

3. Os elementos característicos destas definições são:

I - A Economia é uma ciência.

II - A Economia estuda as atividades econômicas ou as coisas gerais de que depende o bem estar material - ou a riqueza.

III - A Economia estuda os homens em sociedade.

4. Examinemo-los separadamente.

I - A palavra ciência, desacompanhada de qualquer adjetivo, não tem significado tão constante e invariável que nos autorize a rotular um estudo de ciência sem provocar ambiguidades. Com efeito, a Economia é uma ciência positiva ou normativa? Por outras palavras: preocupa-se ela com o que é ou com o que deve ser? A Economia é uma ciência pura ou aplicada? Ou melhor: pesquisa os conhecimentos desinteressadamente ou porque são pràticamente úteis? Eis algumas indagações que não encontram respostas nas definições citadas. Sem dúvida - como diz LINDLEY FRASER - a definição de KEYNES ainda poderia ser aceita se a Econiomia versasse menos condições reais do que ideais, ou se visasse a ser pràticamente útil ao invés de teòricamente verdadeira. Não foi, porém, o que o seu autor escreveu sequer implìcitamente.

(2) Lionel Robeins, op cit., caps. I, II, V e VI de modo especial.

(3) ERICH Roli, op. cit., Part I (1, 2, 3, 4 e 5) e Parte II (I. 1, 2, 3, 4 e 5).

(4) J. N. Keynes, Scope and Method, p. 101, apud Lindley Fraser: op. cit. p. 21 .

(5) Cannan, Wealth, p. 17, apud Lindley Fraser, op. cit., p. 24.

(6) Cannan, Elementary Political Economy, p. 1 apud LIONEL RoBbins: op. cit. p. 2 .

(7) Alfred Marshall, Principles of Economics, p. 1. 
5. II - Sem atentarmos no círculo vicioso com que êste novo elemento - "atividades econômicas" - contribui para a definição da ciência que ora nos ocupa, seria oportuno registrarmos dois importantíssimos dados trazidos à melhor compreensão do assunto:

a) Se o adjetivo - econômico - está empregado, aqui, no sentido habitual, isto é, querendo especificar que a atividade em questão se propõe aumentar a reserva de bens, de riquezas ou a prosperidade dos homens, então a Economia estuda as atividades relacionadas com a produção e a apropriação da riqueza;

b) Se os indivíduos nem sempre se conduzem de maneira a multiplicar as suas riquezas, infere-se que em circunstâncias muito freqüentes da vida quando se distraem ou lêem um romance policial, ao invés de trabalharem - a Economia não lhes estuda as atividades. Ela preocupa-se, portanto, sòmente com uma seção ou um departamento da conduta humana, a saber: aquela seção ou aquêle departamento que assegura a felicidade ou o bemestar material. Ora, se assim fôr, a vida inteira de certas afortunadas criaturas - como observou FraSER - e boa parte da do comum dos mortais, não será objeto das cogitações da Economia.

6. Se dissermos - conforme sugeriu Marshall - que a Economia é o estudo do Homem nos negócios comuns da vida, seremos levados à mesma conclusão a que êle chegou, isto é, que a Economia é a ciência da Riqueza. Mas... que vem a ser riqueza? Eis a palavra crucial de tôdas essas definições - comenta FraSER; cumpre examiná-la cuidadosamente para fixar c que ela implica.

Passemos de largo sôbre o sentido vulgar que o têrmo apresenta - abundância do que quer que seja: "riqueza de expressões ou riqueza de flôres"; e consideremos o outro sentido, que não é mencs corrente - posses materiais: "é um homem de grandes riquezas: tem fazendas, haras, propriedades urbanas e terrenos em bairros de indiscutivel futuro"! A terminologia econômica tem preferido esta última acepção; assim, riqueza seria um conjunto, grande ou pequeno, de objetos materiais. Nem sempre, contudo, são êles uma riqueza; só passarão a esta categoria se forem úteis (isto é, se satisfizerem a uma necessidade humana) e, pelo menos potencialmente, permutáveis. A permutabilidade, por seu turno, acarreta - transferibilidade física e raridade ou escassez. Os bens gratuitos, como o ar, não constituem objeto de negócio, porque existem em superabundância; semelhantemente, não se troca o próprio corpo, p.ex., porque êle se não transfere a outrem. Isto pôsto, o significado particular que o têrmo riqueza adquiriu na terminologia econômica foi o de "meios materiais e permutáveis que satisfazem às necessidades humanas". A Economia é, portanto, a ciência que trata da produção e da apropriação dêsses meios.

7. III - A limitação imposta ao estudo da Economia pelo terceiro elemento - "em sociedade" - suscita a questão, já largamente versada por muitos autores, da existência de uma economia isolada ou da economia de um Robinson Crusoe. 
Ainda que alteremos ligeiramente os dados do problema, à maneira de Bergson, (8) ao afirmar com muita finura que Robinson Crusoe conservou nos anos de segregação, antes que Sexta-feira the aparecesse, a "memória da sociedade", ainda assim o problema persiste e não é, diga-se logo de entrada, fácil ou irrisório.

O interêsse que apresenta, talvez pudesse ser resumido nestas indagações: Qual a área de aplicabilidade dos resultados da ciência econômica? É uma ciência puramente social, que investiga, apenas, os fenômenos de troca individualista ocorridos em sociedade? Ou inclui a Economia, no seu âmbito de preocupações, a vida de um homem em uma ilha deserta? Atende ela, porventura, à vida econômica de um estado comunista ou de um estado escravo?

Não nos forremos à evidência de que uma sociedade, onde impere a troca individualista, é o campo de eleição para os estudos econômicos, pois, em verdade, tal sociedade poderia enquadrar-se tanto nos países capitalistas dos últimos séculos, como em tôdas aquelas formas propostas de comunidade socialistas, em que o Estado possui os meios de produção e controla o seu processo, deixando aos cidadãos o direito de decidir onde oferecer trabalho e o que comprar. Tal sociedade caracteriza-se pelo sistema de preço; a Economia constituirá, portanto, o estudo pelo qual a produção e o consumo são controlados pelos preços. No entanto, é incontrastável que em qualquer economia existe um problema econômico: Robinson Crusoe esforça-se por produzir utilidades e é obrigado a poupar os seus recursos; na Antiguidade ou na Idade Média, sob o regime da escravidão ou da servidão, havia empenho por parte dos homens em criar riquezas e não se perdiam de vista as épocas de penúria; e, na Rússia, semelhantemente, há interêsse pelos fenômenos de abundância e escasssez, de economia e desperdício. (9).

A expressão economia isolada, segundo esclarece ERICH RoLl, não se aplica tão sòmente a Robinson Crusoe na sua ilha deserta, mas circunscreve também o caso de uma economia social planificada por autoridade central; "a essência de uma economia isolada é, conseguintemente, a existência de um contrôle único sôbre os meios, de uma vontade única determinando-lhes a disposição". Assim, "as generalizações da teoria do valor são tão aplicáveis à conduta do homem isolado ou à autoridade executiva de uma sociedade comunista, como à conduta do homem em uma economia de troca". (10)

(8) "Mais il (BERGSON se refere ao homem que pretendesse isolar-se da sociedade) ne le pourraitt pas, même s'il le voulait, parce que sa mémoire et son imagination vivent de ce que la societé a mis en elles, parce que la societé est immanente au langage qu'il parle, et que même si personne n'est là, même s'il ne fait que penser, il se parle encore à lui même. (...) Même matériellement, Robinson dans son ile reste en contact avec les autres hommens (...) Mais un contact moral lui est plus nécessaire encore, car il se découragerait vite s'il ne pouvait opposer à des difficultés sans cesse renaissantes qu'unz force individuelle dont il sent lez limites." (HENRI BERGSON, Les detix sources de la morale et de la religion, Félix Alcan, 1937 p. 9.)

(9) LINDLEY FRASER, op. cit., p. 44.

(10) ERICH Rall, op. cit. p. 42; LIONEL RobBins, op. cit., p. 20. 
8. Se quisermos resumir os resultados da simplificação, às vêzes violenta, que fizemos das definições do tipo A, poderemos dizer:

a) São definições "departamentalizadoras" ou "classificadoras", isto é, escalam certas espécies de conduta humana como objeto de estudo da Economia e excluem as demais da investigação a que se venha proceder;

b) São definições imprecisas visto que não distinguem a Economia de outros estudos humanos;

c) São positivas; não são normativas, porque se limitam a indicar toscamente o que os economistas de fato examinam, sem estabelecer o que êles deveriam examinar.

9. A refutação das definições do tipo A pode ser feita, de modo sumário, com um ou outro dos pequenos problemas que LIONEL ROBBINS formulou, e que jamais obteriam esclarecimento, ao menos teórico, por parte da Economia, se o campo de investigação da ciência fôsse tão acanhado como MARSHALl ou CANNAN pretenderam.

10. Não haverá ironia, porventura, quando RoBBINS indaga se a teoria do salário é parte integrante de qualquer sistema de análise econômica? Há certamente mais que ironia; há maldade. Porque, se aceitarmos as definições do tipo $\mathrm{A}$, seremos obrigados a admitir, de boa vontade ou a contragosto, aquela distinção hoje por todos rejeitada e ninguém a contestou com melhores argumentos que o próprio CANNAN - entre o trabalho produtivo e o improdutivo. Vale a pena recordar o trecho imortal em que ADAM SMITH (11) propôs êsse conceito de produtividade. "O trabalho de certas respeitabilíssimas ordens da sociedade é improdutivo de qualquer valor como o dos empregados domésticos, e não se fixa ou concretiza em objeto permanente ou utilidade vendável, que perdure depois da labuta haver passado. (...) O soberano, p. ex., bem como todos os funcionários da justiça e da guerra, que the estão subordinados, são trabalhadores improdutivos. (...) na mesma classe cumpre incluir as mais graves e importantes profissões e algumas das mais fúteis: sacerdotes, advogados, médicos, homens de letras quaisquer que sejam: atores, palhaços, músicos, cantores de óperas, bailarinas, etc.”. Ora, o salário que se recebe pelo exercício de uma profissão improdutiva - seja ela grave, importante ou fútil - não pode ser caprichosamente excluído daquela parte da teoria econômica que se esforça por esclarecer os problemas relacionados com os tipos de remuneração de trabalho, isto é, não pode ser excluído da teoria do salário. Mas, como será possível advogar essa inclusão se definimos a Economia como o estudo das riquezas, ou do lado material da felicidade humana, ou das causas gerais de que depende o bem-estar material? Se o indivíduo nada produz de palpável, se o resultado do seu trabalho não se fixa nem concretiza - usemos os verbos de ADAM SMITH a fim de assegurar duradouramente a si mesmo ou aos seus semelhantes, uma parcela de bem estar material, como admitir que a remuneração que lhe foi estipulada possa merecer a atenção dos economistas? LIONEL ROBBINS condensa admiràvelmente a questão: "Seria intolerável uma teoria do salário que ignorasse tôdas aquelas somas que são pagas pelos serviços "imateriais" ou gastas, na satisfação de

(11) ADAM SMITH, The Wealth of Nations, Livro II, cap. III, p 315 (ed. CANNAN). 
fins imateriais. $\mathrm{O}$ círculo da troca ficaria irremediàvelmente rompido. $\mathrm{O}$ processo de análise geral nunca poderia ser empregado na sua inteireza. E impossível conceber generalizações significativas em um campo assim tão arbitràriamente delimitado". (12)

11. Os dias tumultuosos em que vivemos e de que tanto falam os publicistas sugerem-nos freqüentemente considerações sôbre a "economia de guerra". Uma economia de guerra seria uma "contradictio in adjecto" - declara enfàticamente o Prof. CANNAN, baseando a afirmação, sem dúvida alguma, no fato de que a guerra não é causa do nosso bem estar material e, assim, não pode constituir objeto de preocupação do economista. Ora, nada há mais duvidoso - comenta LiONEL RoBBins - do que os organizadores da guerra dispensarem a ajuda, que a Economia lhes traz, no esclarecimento das condições de que a guerra mesma depende.

12. Há, portanto, nas definições de Economia do tipo A, uma incapacidade manifesta de descrever o verdadeiro objeto formal da disciplina. E como só a formalidade do objeto diversifica uma ciência, eis aí porque essas definições são imprecisas e não diferençam a Economia dos outros estudos do Homem. Este, em verdade, indistintamente considerado, é objeto material de tôtas as chamadas ciências sociais (cu morais, como antigamente se preferia). O ponto de vista, que escolhemos para considerá-lo, é que permite fixar o objeto formal e, assim, conhecer em que se distinguem umas das outras as ciências vinculadas por aquela materialidade de objeto.

13. As definições do tipo $B$, propostas pelos autores anteriormente citados, não revelam as incongruências que foram agora apontadas. No intuito de assinalar com precisão o aspecto econômico que uma ação humana qualquer porventura apresente, utiliza LIONEL RoBBins postulados básicos que lhe parecem decorrer espontâneamente da própria natureza do Homem. Acompanhemos o seu raciocínio, exposto, aliás, com tal vigor e sutileza, que se torna quase avesso a uma simplificação.

Quando consideramos o homem isolado - entidade que se presta de modo particularmente vantajoso aos esforços de abstração ensaiados nas ciências sociais - verificamos que êle divide o seu tempo entre o repouso e a produção. A perplexidade em que fica, ante a contingência dessa divisão, imposta pela natureza, apresenta aspecto econômico. Quais as condições indispensáveis à existência dêsse aspecto econômico na conduta do homem isolado? Em primeiro lugar, êle carece igualmente de repousar e de produzir. Em segundo lugar, êle não dispõe de tempo bastante para consagrar ao repouso e à produção. Em terceiro lugar, êle empregará o tempo de que dispõe, ou repousando mais, ou incrementando a produção. Em quarto lugar, é lícito supor-se que sejam de importância diversa a necessidade de produzir e a de repousar. "Cumpre-lhe, portanto, escolher, economizar - observa Roneins. Cumpre-lhe relacionar o tempo e os recursos que tem ao seu sistema de necessidade"

"As condições da existência humana apresentam, (portanto), quatro características essenciais do ponto de vista do economista. Os fins são vários.

(12) LiONEL RoBbins, op. cit., p. 6. 
O temfo e os meios para alcançar êsses fins são limitados e suscetiveis de aplicação alternativa. E, ao mesmo tempo, os fins têm importância diferente". (13)

14. Dizia o Apóstolo que havia muitos homens dentro dêle, que o compeliam a efetuar constantemente atos inexplicáveis. Não nos diferençamos em essência do grande Santo: se não sentimos o império de tantas vontades, porque às vêzes nem sabemos querer, os nossos desejos e tendências instintivas (as necessidades biológicas e as sociológicas de FILIPPO CaRLI) também nos solicitam contraditòriamente. Apesar de inumeráve1s e urgentes podem os nossos fins, todavia, ser hierarquizados, de forma a estabelecermos uma prioridade na satisfação eventual dos mesmos, pois nem todos são de igual importância. O tempo é que é limitado e o mundo exterior escasso de bens, conquanto haja quem ainda acredite firmemente que a época da abastança não se acha longe e que os economistas pedem "a paralização do progresso científico numa ocasião da história mundial em que a ciência aboliu a necessidade de pobreza"... (14) Como seria possível, porém, atender à multiplicidade de fins, embora já hierarquizados, se os meios - tempo, elementos materiais ou! serviços dos nossos semelhantes - escassos como são, não fôssem suscetíveis de apiicação alternativa? Consumimos, assim, vida e recursos limitadíssimos para satisfazer aos próprios e aos alheios ubjetivos, mediante muitas vêzes uma precária graduação de valores.

Atente-se, porém, no seguinte: a variedade de fins ou a escassez de meios não basta, isoladamente, para suscitar um fenômeno econômico. Nem a aplicabilidade alternada de meios raros nem a graduação de fins em ordem de valor, dissociadamente, é suficiente também para que exista êsse fenômeno. O economista só discernirá um aspecto econômico na conduta humana, quando as quatro características mencionadas coexistirem interdependentemente.

$\mathrm{E}$ por que são estas características, quanto consideradas de per si, incompletas e, tomadas em conjunto, complementares? Porque só a coexistência delas impõe ao homem a necessidade da escolha. Sempre que houvermos optado por certos fins em detrimento de outros, sem dúvida teremos procedido prèviamente à hierarquização de todos, em função do tempo e dos recursos de que dispomos. $\mathbf{E}$ essas escolhas, que afinal se traduzem em atos, interessam ao economista, porque nelas a sua observação de estudioso distingue uma condição constante que determina a conduta humana: a escassez. Parece-nos ocioso recorrer a longas digressões biológicas para afirmar a natu-

(13) Lionel Robbins, op. cit., p. 12/16; no mesmo sentido: ERICH Roll, op. cit., 9/17; expondo lucidamente a questão, pôsto que não siga a RoBBins em todo o seu raciocínio: LINDLEY FRASER, op. cit., p. $29 / 41$ e 375.

(14) Enid Charles, The Twilight of Parenthood, Watts \& Co. London, 1934. p. 31; LIONEL ROBBINS, p. 32/35: "Eoonomics is not an aggregate of the technologies. Nor is it an attempt to select from each the elements common to several. ... The technical arts of production are simply to be grouped among the given factors influencing the relative scarcity of different economic goods. ... To use Professor MAXER's very elegant way of putting the distinction, the problem of technique arises when there is one end and a multiplicity of means, the problem of economy when both the ends and the means are multiple". 
reza relativa do conceito de escassez (15); esta existe sempre que a quantidade de uma coisa deixar de ser ilimitada em relação às necessidades; só em sentido particularíssimo como êsse é que a escassez se torna a característica de um problema econômico. Eis então em que consiste a unidade do objeto da Economia: "as formas que reveste a conduta humana ao dispor de meios escassos". (16)

15. Serão necessários exemplos que reforcem as idéias expostas?

Se adotarmos alguma das definições do tipo A ficaremos embaraçados, como já tivemos ocasião de sugerir, com a resolução de pequenos e ridículos problemas. As cozinheiras exercem atividade produtiva; ao economista, pois, o exame do que haja de relevante no trabalho culinário. As bailarinas, que arrastam multidões ao teatro e cujas representações se disputam a alto preço, essas devem ficar apartadas das observações do mesmo estudioso: são improdutivas. No entanto, é bem mais simples admitir-se que os serviços de uma e de outra são limitados em relação às necessidades que há (mais precisamente: em relação à procura) e podem ter empregos alternativos. A teoria do salário não deixará agora, mesmo parcialmente, de enquadrar-se no sistema geral da análise econômica.

O problema da economia de guerra, que arrancara a tão grancle autoridade, como o Prof. CANNAN, tão categórica afirmativa - é uma contradictio in adjecto - êsse ficará perfeitamente acomodado à definição que recorrre ao conceito de escassez: porque, em verdade, o prosseguimento feliz de uma guerra implica na destinação de serviços e bens escassos a fins diferentes dos habituais; tem, portanto, um aspecto econômico.

16. "O economista estuda a disposição de meios escassos. Interessa-se $n 0$ modo por que diferentes graus de escassez de diferentes bens dão lugar a proporções diferentes de avaliação entre êles, e interessa-se no modo pelo qual modificações em condições de escassez, quer provenham de alterações nos fins, quer de alterações nos meios - do lado da procura ou do lado da oferta afetam a essas proporções. A Economia é a ciência que estuda a conduta humana como uma relaão entre fins e meios escassos que têm usos alternativos. (The economist studies the disposal of scarce means. $\mathrm{He}$ is interested in the way different degress of scarcity of different goods give rise to different ratios of valuation between them, and he is interested in the way in which changes in conditions of scarcity, whether coming from changes in ends or changes in means from the demand side or the supply side-affect these ratios. Economics in the science which studies humam behaviour as a relationship betiveen end's and scarce means which have alternative uses). (17)

(15) "A rigor não seria exagêro dizer que a produção mundial de alimentos poderia ser aumentada muitas vêzes, sem alargar a área de cultivação, se o gênero humano explorasse à saciedade todo o conhecimento científico de que já dispõe. Se o asserto parecer exagêro ou simples conjectura, basta observar que a Escola de Agricultura de Cambridge, em condições normais de trabalho, obtém invariàvelmente uma collheita de 60 bushels pot acre de trigo em comparação com a média de 32 em todo o país." (ENID CharLes, op. cit. p. 30.) - Os conhecimentos científicos são, no entanto, escassos.

(16) LIONEL RobBins, op. cit., p. 15; ERICH Roll, op. cit., loc. cit.

(17) LIONEL RoBBins, op. cit., 16. No mesmo sentido, vejam-se os autores citados por LONEL RoBBINS: MENGER: Grundsaetze der Volkwirtschaftslehre; MISES: Die Gemeinwirtschaft; Fetter: Economic Principles STRIGL: Die Oekonomischen Kategorien 
17. As conclusões mais importantes, proporcionadas pela definição de RoBBINs, conforme o juízo de FRASER e do próprio autor, são as seguintes:

a) Inspira-se a definição no desejo de dar à Economia um status pde ciência teórica e positiva, embora não lhe arrebate a possibilidade de tornar-se normativa;

b) É uma definição analítica ao invés de classificadora; considera um aspecto e não um gênero de conduta; é abstrata, teórica e formal: não emite julgamentos históricos, mas universais;

c) É precisa e exata: logo se verifica se um determinado problema poderá ser chamado econômico ou não. (18).

18. A possibilidade de aplicação, à teoria de orçamento, dos postulados básicos que integram a definição de RoBBINs, parece-nos perfeitamente viável e até mesmo proveitosa. Não é necessário sustentar que o Estado se assemelha a um organismo para que se admita, sem esfôrço, a similitude existente entre a conduta do indivíduo, quando procura atender aos seus fins qualquer que seja a economia em que viva - e o exercício das funções estatais, expresso monetàriamente no documento orçamentário. Não são os homens sòmente que têm de proporcionar meios escassos com usos alternativos a fins vários e concorrentes. Não são ùnicamente os homens que se vêm ante a dura contingência de escolher qual a necessidade mais premente a que devem satisfazer, quando tantas estão a clamar no íntimo de cada um. Não são os homens apenas que fornecem à Economia unidade de objeto: "as formas que reveste a conduta humana ao dispor de meios escassos". Também o Estado moderno, cujas funções e cujo poder se multiplicam extraordinàriamente, a ponto de quase nãc existir atividade que the seja desconhecida ou fôrça que se the equipare (19) - também o Estado moderno se defronta com embaraços semelhantes. A um desdobramento crescente de funções estatais nem sempre vem correspondendo, em nosso atormentado mundo contemporâneo, um volume idêntico de meios financeiros. Não há hoje quem vacile em reclamar a assistência dos poderes públicos para os casos mais estranhos às antigas atribuições que thes haviam sido cometidas, e quem não deseje - observa SHIRRAS (20) - as coisas que tornam os impostos altos, mas ninguém se conforma em que êles sejam altos. "O govêrno do povo, pelo povo, para o povo não é forma barata de govêrno e é muito mais dispendiosa do que o govêrno absoluto", (21) contudo ainda alguns se referem à tributação progressiva empregando

und die Organisation der Wirtschaft. Precisando mais o seu pensamento diz RoBBINS à p. 38: "... The subject matter of Economic is essentially a series of relationships between ends conceived as the possible objectives of conduct, on the one hand, and the technical and social environment on the other. Ends as such do not form part of this subject-matter. Nor does the technical and social environment. Is is the relationships between these things and not the things in themselves which are important for the economist".

(18) LIONEl RobBins, op. cit., p. 16/23; Lindley Fraser: op. cit. p. 41.

(19) Benedito Silva: Ensaio de análise do Estado moderno, "Revista do Serviço Público", janeiro de 1939; v. especialmente a conclusão.

(20) G. Findlay Shirras, op. cit., vol. cit., p. 50.

(21) G. Findlay Shirras, op. cit., vol. cit., p. 53. 
aquela expressão revoltada de STUART MrLL, tão característica do espírito liberal do século XIX - roubo gradativo - Impõe-se ao Estado moderno, por isto mesmo, o dever de equilíbrio orçamentário (22) - real e não ilusório já que o plano de trabalho governamental, ciclicamente renovado, é condição imprescindivel ao exercício ordenado e eficiente das suas funções. Mas, como alcançá-lo se não pela renúncia, ao menos temporária, de algumas ou pelo exercício incompleto de outras, tal como se observa nas necessidades do indivíduo? A hierarquização das despesas que ocorrem às funções estatais deriva, portanto, da competição que entre estas se trava: o que o Estado arrecada ou toma emprestado não basta, por certo, para que tanto as funções essenciais como as opcionais - conforme a classificação bem conhecida de RAYMOND GETTEL - consigam ser exemplarmente atendidas. Ao Estado, pois, não são estranhos os problemas de escassez e abundância; não the são estranhos, em suma, os problemas de fins concorrentes, que importa hierarquizar, para que melhor proveito retire dos meios escassos de que dispõe; daí a classificação que se deve a SHIRRAS, tão lógica e tão simples, grupando as despesas públicas em despesas primárias e secundárias, aquelas equivalendo às funções essenciais e estas às opcionais. (23)

19. Um exemplo, no entanto, elucidará muito mais persuasivamente a exposição. Diz LEonaRd D. White (24) que, entre os traços assustadores da história administrativa dos Estados Unidos, figurava a ausência, nos governos estaduais até 1910 - no govêrno federal até 1920 - de orçamentos executivos. As repartições dirigiam-se diretamente aos corpos legislativos; e êstes, com magnífica liberalidade, iam outorgando as dotações solicitadas, sem atentar nas "possibilidades de extravagância, desperdício ou favoritismo, que eram infinitas sob a vigência de tão desorganizado regime." "Um programa financeiro, sólido e equilibrado, era desconhecido, o proporcionamento adequado das despesas à receita relegava-se ao segundo plano e os deficits eram tão comuns como os mosquitos em Nova-Jersey". Só um país abençoado com economia em rápida expansão - conclui êle - poderia ter suportado a falta de ordem financeira que se generalizara há algumas décadas.

O grande mestre da Administração Pública localiza, com estas informações pitorescas e melancólicas, o núcleo essencial da questão. Ao Estado cumpre, em verdade, organizar periòdicamente o seu programa financeiro e de trabalho, de forma tão precisa e completa quanto the seja dado, sob pena de mergulhar no caos. Cumpre-lhe ajustar fins vários a meios escassos com usos alternativos e à teoria econômica do orçamento incumbe estabelecer as normas ideais para alcançar essa meta. Que nenhuma necessidade habitual deixe de ser prevista com inflexível rigor, porque já hoje não se ignora que, "à parte casos de urgência especiais" - como diz BASTABLE - "a despesa se acha perfeitamente dentro do campo das previsões racionais"; (25) que as possi-

(22) A. E. Buck, The Budget in Governments of to-day, p. 116.

(23) G. Findlay Shirras, op. cit., vol. cit. p. 90/93.

(24) LEONARD D. WhITE, Introduction to the study of Public Administration, New York, The Macmillan Company, 1939, p. 211/213; HARVEy Walker, Public Administration in the United States, Farrar \& Rinehart, New York, 1937, p. 202.

(25)

A. E. Buck, The Budget in the Governments of to-day, p. 175. 
bilidades tributárias sejam computadas por métodos desapaixonados e diretos; e que $\sigma$ ajustamento das despesas à receita seja feito sinceramente (e sincerus, em latim, quer dizer puro...) para que se possa fugir acs equilíbrios ilusórios, aos equilíbrios no papel - eis aí o que importa ao Estado empreendedor e forte dos nossos dias. O sistema orçamentário é pois, condição de vida do Estado moderno. E o equilíbrio, "indubitàvelmente, o traço mais essencial ao orçamento". (26)

20. Qual o princípio, todavia, que deve nortear o Estado moderno nas despesas que efetua, para bem exercer as funções que the vem impondo, tumultuosamente, a industrialização da sociedade? Qual o princípio a que deve obedecer em tributação, já que os melhores economistas tendem a reconhecer no mesmo Estado um fator de produção? (27)

O maior teorista político do nosso tempo - HAROLD LASKI (28) - responde a estas perguntas de maneira incisiva e clara: $\mathrm{O}$ princípio supremo a que o Estado deve submeter-se e que o deve orientar é sempre o do bem social.

"Pois o bem, cumpre acentuá-1o" - escreve êle - "ou é social ou não é bem absolutamente. Se o homem tem de viver em comunidade com os seus semelhantes, é condição necessária à sua vida que o que obtenha, pelo menos à medida que o tempo decorre, também acarrete benefício para os outros (...) O bem social é, assim, aquêle imperativo da nossa personalidade que nos leva a procurar as coisas que vale a pena serem obtidas, a fim de que, por meio delas, possamos enriquecer a grande comunidade a que servimos." "... O Estado vem tornando-se uma organização destinada a habilitar os homens à realização, na maior escala possível, do bem social. (...) E parece que é levado cada vez mais a controlar de certa forma, essas evidentes utilidades, tais como água, eletricidade, ou transporte, de que o bem estar dos seus membros tão intimamente depende".

Ora, o princípio do bem social, de que fala o professor inglês, não é outro - se o aplicarmos às despesas públicas - senão o princípio da máxima vantagem ou da máxima felicidade social, (29) e - se o aplicarmos à tributação - o princípio do mínimo sacrifício coletivo. (30) São princípios supremos e utilitários; objetivos reguladores das despesas e das rendas públicas.

21. Os princípios que vimos de citar conferem, efetivamente, à hierarquização das despesas e das rendas públicas um caráter de objetividade, que às vêzes falta, por exemplo, à do consumo particular. A utilidade individual, ninguém o ignora, é subjetiva e relativa: "expressa apenas" - diz ERICH RoLI (31) de modo incisivo e perfeito - "uma relação entre o indivíduo e um

(26) A. E. Buck: op. cit., p. 115.

(27) LiNDLEY Fraser: op. cit., p. 211.

(28) Harold Laski: A Grammat of Politics, George Allen 8 Unwin, London, 4. ${ }^{\text {a }}$ ed., 1938, p. 26 passim.

(29) G. Findlay Shirras, op. cit., vol. cit. p. 77/78.

(30) A. C. Pigou, op. cit., Parte II. cap. I; G. Findlay Shirras, op. cit., vol. cit., p. $307 / 309$.

(31) ERICH ROLL, op. cit., p. 53. 
objeto, do ponto de vista do problema da satisfação das necessidades". A utilidade individual é, pois, flutuante e circunstancial; varia em função dos nossos desejos. A utilidade social, conquanto não deixe de ser algo relativa, firma-se porém, em bases mais sólidas; se é difícil precisá-la, não nos faltam elementos graças aos quais seria possível fazer a tentativa. Podemos concebê-la, neste momento histórico, mais objetiva e rigorosamente, graças às transformações de tão grande alcance, provocadas, a partir da Revolução Industrial, por uma intensa mobilidade social, e em seguida à subversão por que passaram o conceito de bem estar público e as diretrizes de política social dêle decorrentes. (32) A aplicação dos princípios da máxima vantagem social e do mínimo sacrifício coletivo - espécie de um gênero maior: o princípio do bem social - às despesas públicas e à tributação - é, assim, o critério mais seguro para hierarquizar as primeiras e estabelecer os ônus a serem impostos pela segunda às várias classes que integram a sociedade.

O indivíduo gradua os seus fins, de modo a poder satisfazê-los, ponderando não só a importância de cada um, mas também a quantidade de bens de que dispõe. Por nutras palavras: não the basta comparar os fins e estabelecer uma escala de preferência, porque a sua avaliação depende, também, do uso marginal que uma reserva de bens pode ter. (33) Seu processo é, portanto, parcial e relativamente subjetivo.

O Estado hierarquiza, ou deveria hierarquizar, as despesas públicas os fins a que procura atender - consultando o princípio da máxima vantagem social - que não é tão indefinido como pode ser o nosso subjetivismo e adstrito às rendas que espera arrecadar. Seu processo é uma decorrência dos meios de que vai dispor, temperado pelas diretrizes políticas e sociais adotadas.

Semelhantemente, o Estado impõe o gravame da tributação aos seus membros, norteado pelo princípio do mínimo sacrifício coletivo, mas sem perder de vista, ao mesmo tempo, as despesas compulsórias a que deve atender. Seu critério é uma consequiência de fatôres econômicos e sociais somados aos imperativos decorrentes da condição do Estado, que existe para servir e proteger.

(32) Legitimando a idéia de que a utilidade social varia com o ambiente histórico e cultural: "O que efetivamente varia é a cultura ou a herança social ( ...) A explicação das nuutações pode ser procurada nạs invenções. A palavra, tal como aqui a empregamos, significa qualquer elemento novo na cultura - um significado muito mais largo do que o que the é ordinàriamente atribuído. Considerando a cultura como um todo, a fôrça que concorre para a mutação é a criação de um invento. Considerándo uma área cultural particular, a mutação social se deve a uma invenção que nela se tenha registrado ou que haja sido importada. Para compreender as mutações sociais é necessário conhecer como as invençóes se fizeram e ccmo se difundiram ( ...). As mutações sociais são agora mais numerosas que os elementos culturais". (WILliam F. OGBURN, Social Change; in Encyclopaedia of the Social Sciences); "... these cultural changers were in early times rather infrequent, but $(\ldots)$ in modern times they have been occuring faster and faster until to-day mankind is almost bewildered in his effort to keep adjusted to these ever-increasing social changes. This rapidity of social changes may be due to the increase in inventions which in furn is made possible by the accumulative nature of material culture". (OGBURN, WILLIAM FIELDING, Social Chanke (with respect to culture and original nature) - Vikburg Press, New York, 1938; p. 199/200.)

(33) ERICH ROLL: op. cit. p. 61. 